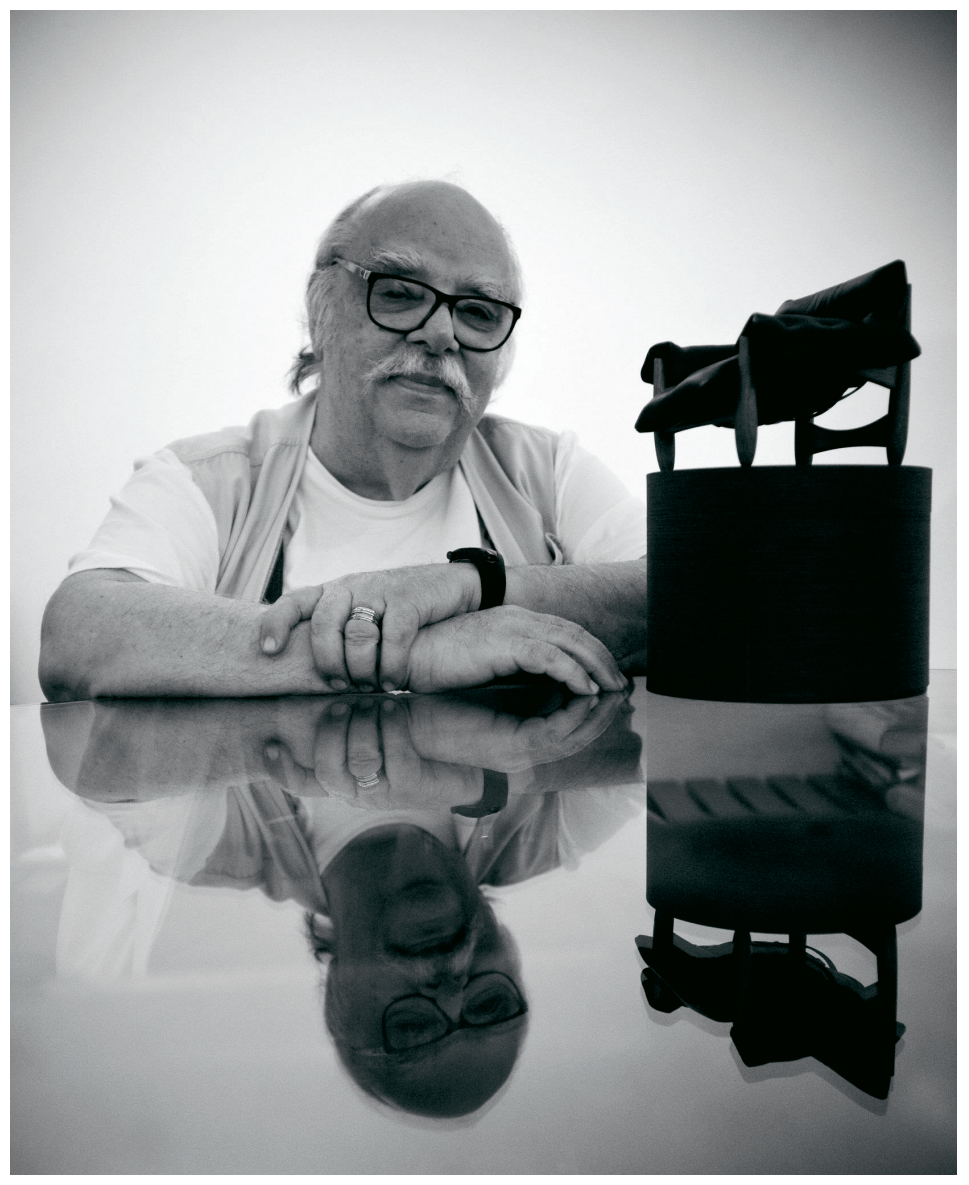




\section{Melancolia do moderno: móveis esquecidos de Sergio Rodrigues.}

\section{Modern melancholy: Sergio Rodrigues' forgotten furniture.}

palavras-chave: móveis de escritório; mobiliário moderno; Sergio Rodrigues;

Casa do Brasil; palácio Pamphili

keywords: office furniture; modern furniture; Sergio Rodrigues; Casa do Brasil; Pamphili

Palace

* Universidade de Brasília [UnB].

DOI: 10.11606/issn.2178-0447. ars.2017.123176.
Ainda que Sergio Rodrigues tenha ficado notoriamente conhecido por sua poltrona Mole, não se pode esquecer de uma série de móveis desenhados por ele para escritório, que viriam a cumprir outra função na arquitetura. Eles foram concebidos pelo arquiteto para a Casa do Brasil em Roma, no palácio Doria Pamphili. Móveis que por sua funcionalidade foram esquecidos, mas que guardam no seu desenho, material e concepção final algo do mesmo otimismo inscrito na construção de Brasília. Quando se anda pelas salas e corredores da Casa Brasil, tem-se a impressão de que objetos, pinturas e particularmente os móveis traçam com exatidão cristalizada qual foi a contribuição das artes no período desenvolvimentista brasileiro.

If Sergio Rodrigues would famously known to his Poltrona Mole, we could not forget a series of office furniture designed by himself, which fulfils another function in architecture. It was the office furniture designed for Brazil's House in the Palace Doria Pamphili, Rome. Furniture that with its functionality have been forgotten, but keep in its design, material and intention something even of the optimism registered in the construction of Brasilia. When one walk through the Casa Brazil's rooms and corridors has the impression that the objects, paintings and especially the furniture shows exactly what was the contribution of the arts to the Brazilian developmentalism period. 
Uma situação inusitada, no ano de 1959, descortinou a possibilidade de criação de uma Casa do Brasil no exterior, local viria a servir a acordos políticos e econômicos, assim como espaço de divulgação de nossa cultura. Isso tudo com um detalhe muito peculiar, surgiria ali uma grande vitrine de nosso mobiliário. Quando se fala de móvel nacional aqui, trata-se exatamente do mobiliário moderno, feito por Sergio Rodrigues para a sede da Embaixada do Brasil. De fato, no final de seu exercício como embaixador do Brasil na Itália, em 25 de novembro de 1959, Adolpho Cardozo de Alencastro Guimarães, informou oficialmente o governo brasileiro que a princesa Orietta Doria Pamphili manifestara intenção de vender o palácio onde a Embaixada se encontrava alojada há quarenta anos. Daí surgiu a necessidade de se encontrar alternativa para resolver o problema de alocação da sede da Embaixada brasileira em Roma.

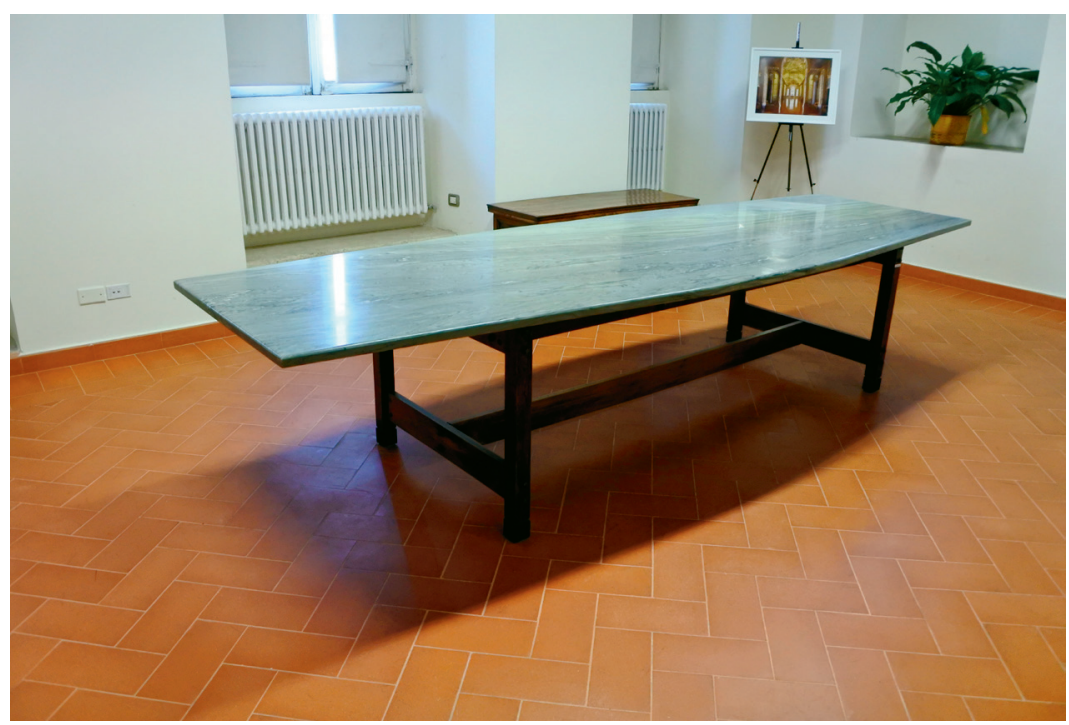

A orientação geral era ou negociar lote na cidade de Roma para construção de uma sede moderna ou comprar e restaurar o próprio palácio Pamphili para que se tornasse sede definitiva da Embaixada. Em princípio do ano seguinte, 1960, não se tinha ainda efetivado uma escolha definitiva do que era o melhor a ser feito, muito pelo contrário. Conforme consta em documentação do início da chefia de Hugo Gouthier de Oliveira Gondim ${ }^{1}$, uma das primeiras iniciativas foi tentar negociar, por compra ou cessão, terreno com a cidade de Roma, em

\section{Marcelo Mari}

Melancolia do moderno: móveis esquecidos de Sergio Rodrigues.

Fig. 1

Mesa Gouthier, $250 \times 120 \times 75$ cm, estrutura de jacarandá maciço, com tampo de granito e guarnições de latão polido, criada por Sergio Rodrigues em 1960. Arquivo particular do autor, 2015.

1. Este artigo foi baseado no livro do embaixador Hugo Gouthier de Oliveira Gondim sobre a Embaixada brasileira em Roma, intitulado Casa do Brasil em Roma: palácio Doria Pamphili; Histórico e Documentação, impresso pela oficina gráfica SEPRO da própria Embaixada, em Roma, no ano de 1963. A intenção de Gouthier era explicitar o esforço de compra, de restauração e de adequação do antigo Palácio Doria Pamphili para ser a sede da embaixada na Itália. A compra do Palácio Doria Pamphili foi iniciativa tomada por Gouthier para resolver o problema de alocação das repartições e órgãos brasileiros em Roma, que por força das circunstâncias, estavam dispersos na cidade e submetidos a preços onerosos de aluguéis. 
conversação oficial com o governo italiano, para construção de um ediano 15 teto Oscar Niemeyer.

Em 02 de março de 1960, o recém-empossado embaixador Hugo Gouthier escreve projeto com exposição de motivos sobre a criação da Casa do Brasil em Roma, revelando preocupação em dar visibilidade ao país no exterior. $\mathrm{O}$ espaço passaria a abrigar portanto não somente a Embaixada brasileira, mas também outros órgãos e repartições dispersadas na capital italiana. Gouthier entendia o projeto como forma de viabilizar de maneira mais eficiente a comunicação entre os diversos órgãos e repartições brasileiras na Itália:

Quando, em novembro de 1959, vim ao Rio de férias, Juscelino me convidou para assumir a chefia da nossa Embaixada em Roma. Agradecido a mais essa prova de confiança do Presidente, comecei sem perda de tempo, e como sempre foi do meu costume, a me preparar para ocupar condignamente e com conhecimento de caso o meu cargo. Minha primeira surpresa foi constatar o número de repartições brasileiras existentes em Roma. Embaixada, Chancelaria, Consulado, Serviço de Imigração, Escritório Comercial, Lóide Brasileiro, Instituto do Café, Instituto Cultural Brasil-Itália, Câmara do Comércio e mais algumas, todas absolutamente indispensáveis ao bom entendimento dos dois países. Preocupado, tratei de entrar em contato com o Grupo Interparlamentar Brasil-Itália, presidido pelo Deputado Ranieri Mazzili, e com o Encarregado de Negócios da Itália, no Brasil, Carlo Enrico Giglioli. Das nossas longas conversas, deduzi que o ideal seria a criação de uma Casa do Brasil, em Roma, capaz de abrigar todas as repartições acima mencionadas, além dos escritórios da Panair e das companhias de turismo e navegação ligadas ao Brasil. Capaz ainda de receber as delegações brasileiras junto à FAO [Organização das Nações Unidas para a Alimentação e a Agricultura] e outras conferências internacionais. Enfim, precisávamos de uma verdadeira Cidade do Brasil dentro da

2. GOUTHIER, Hugo. Presença. Brasília: Fundação Alexandre de Gusmão, 2008, p. 255-256. cidade de Roma. E fomos conversar com Juscelino. ${ }^{2}$

O projeto foi apresentado ao Presidente Juscelino Kubitschek de Oliveira por intermédio do ministro de Relações Exteriores Horácio Lafer e entendimentos com o Deputado Ranieri Mazzilli:

Tal projeto consubstanciou-se na Exposição de Motivos n. 29, (...) do Ministério das Relações Exteriores, pela qual se submetia à consideração do 
126

Presidente da República a ideia da construção, em Roma, de um edifício destinado a abrigar as sedes das diversas repartições brasileiras na Itália. (...) Acrescentava a Exposição de Motivos que a Embaixada do Brasil na Itália deveria procurar obter a doação de um terreno apropriado a tal finalidade e que, na hipótese de não chegarem a bom termo os entendimentos nesse sentido, o terreno seria adquirido pelo governo brasileiro. $\mathrm{O}$ presidente Juscelino Kubitschek, entusiasmado com a ideia, aprovou a Exposição de Motivos com o seguinte despacho: "Aprovado. Recomendo aos Ministérios das Relações Exteriores e da Fazenda tomarem, em caráter de urgência, todas as medidas sugeridas na presente Exposição de Motivos, bem como as complementares que se fizerem necessárias.””

A tentativa de se conseguir sede definitiva para a Embaixada em Roma passou até mesmo por negociação de lote urbano em Roma em troca de lote em Brasília para futura construção da nova embaixada italiana na região central do Brasil. O problema é que ao contrário do lote cedido pelo Brasil, que estava planejado no setor de embaixadas de Brasília, o lote que foi negociado e cedido pela municipalidade romana encontrava-se em região de difícil acesso na periferia da cidade. Nesse caso, o principal problema apontado pelos brasileiros foi a dificuldade de acesso ao local. Como a intenção do governo era construir um prédio moderno e suntuoso, arquitetado por Niemeyer, para a Embaixada brasileira, era preciso de um lote de dimensões consideráveis, o que na região central de Roma tornava-se impraticável tanto por causa do adensamento urbano da cidade como por causa do preço do metro quadrado. A dificuldade de se conseguir um lote bem localizado e em grande dimensão levou o governo brasileiro a abandonar a ideia de construir nova sede.

Trocou-se a solução da construção de nova Embaixada com arquitetura de Niemeyer pela compra do palácio Pamphili. Coube ao embaixador Hugo Gouthier, com apoio do então recém-aposentado Adolpho Cardoso de Alencastro Guimarães e também posteriormente com apoio do deputado paulista Raniere Mazzilli concentrar-se na solução de aquisição do palácio Doria Pamphili. Isso parecia ser a solução mais conveniente e muito útil já que o palácio se encontrava no centro de Roma, em lugar referencial da história local e também com grande afluxo de visitação turística. O relato oficial assim descreve a solução da compra do Doria Pamphili:

\section{Marcelo Mari}

Melancolia do moderno:

móveis esquecidos de Sergio

Rodrigues.

3. Idem. Casa do Brasil em Roma: palácio Doria Pamphili; histórico e documentação. Roma: SEPRO, 1963, p. 12. 
Diante de tais dificuldades, o embaixador Hugo Gouthier decidiu concen-

ano 15

ก. 29

4. Ibidem, p. 14-15.

5. Para o estudo sob re realização exemplar da política cultural no período desenvolvimentista de JK no campo das artes visuais, cito meu artigo: MARI, Marcelo. Exposição em Leverkusen: Mário Pedrosa e a crítica de arte internacional. In: CALHEIROS, Alex;

GONÇALVES, Anderson; MARI,

Marcelo (orgs.). Marxismo

e produção simbólica. São Paulo: Nankin Editorial, 2013, p. 221-238. Para estudo mais específico sobre as características da política para a cultura no período desenvolvimentista, ver: ORTIZ, Renato. Cultura brasileira e identidade nacional. São Paulo: Brasiliense, 2006. trar a sua atenção sobre as possibilidades oferecidas pelo palácio Doria Pamphili. O palácio, em verdade, prestava-se admiravelmente aos objetivos que se tinha em vista. Achava-se situado no coração da cidade, na mais bela praça de Roma, ponto obrigatório de turismo para quantos visitam a capital italiana. Por outro lado, dispunha de esplêndidos salões e de área plenamente capaz de comportar todos os órgãos e repartições que se pretendia reunir na Casa do Brasil. Redigiu, assim, o embaixador Hugo Gouthier um relatório sobre a matéria, encaminhado ao Itamaraty com o ofício-verbal n. 194, de 21 de julho de $1960 .^{4}$

A ideia da instalação da Casa do Brasil na Itália foi acolhida muito bem pelo governo de Kubitschek. O governo brasileiro era responsável, ainda que pesasse a escalada da inflação, por um ciclo dinâmico e virtuoso da economia, o que gerava a expectativa de que grandes perspectivas se definissem para o país. Foi nesse período também que os museus brasileiros, aproveitando-se da situação de destruição e miserabilidade dos países europeus, adquiriram parte substancial de seu acervo internacional. Uma "nova capital" seria construída no país e um palácio do período barroco, referencial de turismo, seria adquirido no centro de Roma. O país crescia em termos numéricos, em ritmo acelerado e surgia na cena internacional com intenção de ingressar no ainda restrito rol de países modernos.

Nessa época, era comum entre as ações do governo de Kubitschek promover uma série de iniciativas para divulgar o Brasil no exterior5 5 . O país que descobrira a si mesmo nas décadas de 1930, 1940 e início de 1950, agora se apresentava ao cenário internacional. Esse período foi marcado pelo processo rápido de industrialização e urbanização das cidades brasileiras, em particular São Paulo, que começou a receber maciçamente pessoas vindas do campo em procura de condições melhores de vida. Essa etapa de modernização de várias cidades ao redor do mundo, no período do pós-guerra, era marcada por fluxos migratórios, estabelecimento de novas condições de vida e trabalho nas cidades e principalmente pelo entendimento da importância da arquitetura e das artes ditas aplicadas na transformação da vida material e simbólica do homem moderno. Não por acaso, um dos símbolos da modernização brasileira naquele momento era a formação, o planejamento e a construção de cidades modernas. 
Foi por isso, justamente, que o material governamental de divulgação do Brasil no exterior trazia a arquitetura e o surgimento de novas cidades como elemento central de época e símbolo da modernização. A arquitetura estava presente no material de divulgação oficial do Brasil e pode-se dizer que foi tema que acompanhou, com centralidade, o debate sobre os processos bem-sucedidos de modernização no país. Além da visão modernizante, corria pela Europa o registro renitente do pitoresco ou do excêntrico no Brasil, país ainda pouco conhecido, mas cujos ritmos e ritos, longe de serem excêntricos, estavam em voga no mundo todo. Referências tanto aos povos indígenas como aos quilombolas, assim como a toda sorte de influências que temperaram a brasilidade, tornaram-se símbolo de um espírito moderno ligado à noção de síntese essencial da sensibilidade e da racionalidade. A esse espírito deve-se a grande referência à rusticidade de nossa arte popular, de nossas técnicas e modos pré-capitalistas de produção.

Faziam parte das iniciativas de divulgar o Brasil lá fora, a produção de exposições de costumes e cultura popular, exposições de pintores e de arte moderna, sobretudo mostras fotográficas sobre a arquitetura moderna brasileira e a construção acelerada de um novo país (com seus museus, conjuntos habitacionais e sua nova capital). Além dessas iniciativas, pelo governo brasileiro criou um centro para definição de elementos articuladores, características fortes e de promoção ideológica de nossa cultura - o denominado Instituto Superior de Estudos Brasileiros.

A compra do palácio, como dito, obedeceu a fator externo à vontade do governo brasileiro, qual seja, a intenção de venda por parte da aristocracia italiana, que se beneficiou também do bom momento da economia brasileira e de política interessada em construir espaços de difusão da boa imagem do Brasil no exterior. Em 12 de agosto de 1960, o presidente Kubitschek assinou aprovação de compra do palácio Doria Pamphili pela cifra total, na época, de Lit. 900.000.000,00 (novecentos milhões de liras) ou US\$ 1.452.000,00 (um milhão, quatrocentos e cinquenta e dois mil dólares):

Em 31 de agosto de 1960, foi assinado, por instrumento particular, um contrato de promessa de compra e venda, no qual eram partes, como promitente comprador, o governo brasileiro, representado pelo embaixador do Brasil em Roma e, como promitente vendedor a princesa Orietta Doria Pamphili. (...)
Marcelo Mari

Melancolia do moderno:

móveis esquecidos de Sergio

Rodrigues. 
Embora o palácio tivesse sido comprado no governo de Kubistchek, ele foi realmente inaugurado no governo de João Goulart. Como se sabe, até hoje a Embaixada do Brasil em Roma se situa no palácio Pamphili, na piazza Navona, número 14. Essa praça histórica de Roma, presente em descrições de vários viajantes, tornou-se tema de estudos, gravuras, pinturas, fotografias de revistas variadas, cartões postais, fotografias de recordação de viagem. O nome Navona tem sua origem no fato de a praça ser derivada de forma elíptica do antigo estádio de Domiciano, do século primeiro da era cristã. Atualmente, a cintura original das arquibancadas é ocupada por prédios em altura uniforme, de quatro ou cinco andares.

Por sua vez, a praça é alcançada por oito pequenas e estreitas ruas. Na praça encontram-se três fontes. No centro ergue-se, desenhada por Lorenzo Bernini, fonte em forma de grande rochedo encimado com obelisco romano de influência egípcia. Esse obelisco foi trazido à praça a mando do papa Inocêncio X e foi alçado sobre rochedo de Bernini. Na parte da praça ao sul desta fonte de Bernini, situa-se em frente ao palácio Pamphili, uma fonte simples que recebeu posteriormente conjunto escultórico de autoria dos escultores Bitta e Zappala no século XIX. No centro da fonte, com espelho de água, o deus Netuno pesca com vigor um polvo, fazem ainda parte da cena divindades e cavalos marinhos.

O palácio Pamphili era já conhecido na época de Gouthier como lugar da Embaixada brasileira na Itália e a proposta do novo embaixador em transformar o palácio em Casa do Brasil resolveria a contento os problemas de alocação de espaços em Roma. O palácio, conforme documento oficial de 1958, tivera em todo seu tempo de serviço ao governo brasileiro, muitos inquilinos que trabalharam pelo Brasil, entre eles, o embaixador Luís Martins de Souza Dantas, o primeiro a ocupar oficialmente o palácio, como representante brasileiro, em 1920:

A partir de então, pouco a pouco, todo o primeiro andar foi sendo ocupado pela Embaixada do Brasil. Entre 1923 e 1931 nele habitou como embaixador Oscar Von Honholtz de Teffé; de 1931 a 1934, Alcebíades Peçanha; de 1935 a 1938, Guerra Duval; de 1939 a 1941, Pedro Leão Veloso. (...) E, 
em 1945, voltou a ser a sede de nossa Embaixada, com o embaixador Pedro de Moraes Barros. (...) Assim praticamente há 37 anos habita o Brasil na praça Navona. ${ }^{7}$

Apesar da vantagem que representava para o Brasil a aquisição do palácio Doria Pamphili, muitos jornais italianos, dois dias depois da venda, manifestaram-se negativamente. Havia um entendimento geral, principalmente da esquerda italiana, de que o patrimônio histórico deveria ser defendido da apropriação de estrangeiros e deveria estar sob a tutela do Estado. Foi o caso de jornais romanos de circulação nacional, tais como Il Messaggero, Paese Sera, l'Unità, entre outros. Este último, órgão de difusão de informação do Partido Comunista Italiano, tratou de fazer crítica do imobilismo do governo italiano sobre a venda de imóveis que eram parte do patrimônio histórico e cultural da Itália. Sua posição era a da linha de defesa nacional, já que (não podemos esquecer) o edifício possuía pinturas seiscentistas de ninguém menos que Pietro de Cortona. Em 19 de outubro de 1960, o jornal l'Unità noticiava que:

O edifício construído aproximadamente na metade de 1600, é obra do arquiteto Girolamo Rainaldi, ao qual o havia comissionado o papa Innocenzo X Pamphili para sua família. (...) O edifício torna-se então propriedade de um estado estrangeiro, como o edifício Farnese que, faz anos, foi adquirido pela Embaixada da França. Palácio Doria Pamphili (...) vendido formalmente e (...) não se pode evitar (...) que seja alienada uma parte assim notável do patrimônio artístico nacional. ${ }^{8}$

De fato, o governo italiano, no pronunciamento de Amintore Fanfani, presidente do Conselho de Ministros da Itália e membro da Democracia Cristã, cumprimentou o governo Brasileiro por ter adquirido o palácio Doria Pamphili ${ }^{9}$. E Gouthier assumiu seu exercício em Roma na Casa do Brasil. Vez ou outra, o embaixador brasileiro tinha de dar explicações sobre o fato de o Brasil ter-se empenhado no cuidado de preservação do palácio. O que foi feito em obra que despendeu dinheiros do governo brasileiro e tornou necessária uma reforma do palácio que incluísse o cuidado e a restauração de seus afrescos barrocos.

Hugo Gouthier empreendeu a reforma e a adequação do palácio Pamphili para receber a Embaixada brasileira e outras repartições. Os afrescos descobertos, em 1961, no palácio eram do século XVII e
Marcelo Mari

Melancolia do moderno:

móveis esquecidos de Sergio

Rodrigues.

7. Palácio Doria Pamphili sede de Embaixada dos Estados Unidos do Brasil. Roma: Istituto Grafico Tiberino, 1958, p. $19-20$.

8. Venduto il palazzo dei DoriaPamphili. L'Unità, Roma, 19 out. 1960, apud GOUTHIER, H. Op. cit., 1963, p. 28.

9. Ibidem, p. 42-43. 
ARS ficaram recobertos por 150 anos, atrás de paredes e tetos falsos. Sua ano 15 descoberta foi amplamente divulgada pela imprensa italiana e eles se n. 29 tornaram objeto de acurados estudos sobre arte barroca romana.

O esquema geral das obras do palácio Doria Pamphili, para sua adequação como embaixada, dividia-se em dois: 1) obras estruturantes e de restauração; 2) compra de móveis, adornos em geral e tapetes. Para as despesas do item de número um foi alocada a quantia de 238.000.000,00 (duzentos e trinta e oito milhões de liras) e para o item dois, o equivalente a 40.000.000,00 (quarenta milhões de liras). A soma do montante gasto na recuperação e adequação do palácio Pamphili para hospedar a Casa do Brasil compreendia uma parte de doações feitas por indústrias nacionais e italianas, tais como Vale do Rio Doce, Metalúrgica Matarazzo, FIAT e Pirelli. Os recursos doados foram 181.479.682,00, cabendo ao governo brasileiro arcar com a maior parte dos gastos, que excederam aquilo que fora previsto nas

10. Em depoimento, Hugo Gouthier dizia: "Consideradas

as quantias despendidas desde a compra do palácio até a instalação, nesse imóvel, das repartições brasileiras sediadas em Roma, verifica-se se que o custo global da Casa do Brasil foi de um bilhão, quatrocentos e trinta e seis milhões, oitocentos e noventa e quatro mil, quatrocentas e doze liras (Lit. 1.436.894.412)." In: GOUTHIER, H. Op. cit., 2008, p. 265-266.

11. Idem, Op. cit., 1963, p. 69-73. projeções iniciais ${ }^{10}$.

Em documento de planejamento das obras consta lista de móveis a serem confeccionados para ambientes e finalidades específicas na futura Casa do Brasil. São eles: 1) mesas para embaixador, com poltronas; 2) mesas para ministro conselheiro e ministro para assuntos econômicos, com poltrona; 3) mesas para secretários de embaixada, com cadeiras de braço; 4) mesas para funcionários administrativos, com cadeiras; 5) mesas para máquinas de escrever, com cadeiras; 6) mesas para telefone; 7) mesas para reuniões, com cadeiras; 8) mesas para distribuição de papéis ${ }^{11}$.

No dia 30 de agosto de 1960, esse documento foi enviado pela Secretaria de Estado à Embaixada do Brasil em Roma para providências. O certo é que já estava acertada a confecção de móveis no documento e Sergio Rodrigues seria seu desenhista e responsável pelo acompanhamento do processo de fabricação, com a cooperação de Olavo Redig e de Carlo Hauner. O que pesou na decisão de Hugo Gouthier de escolher Sergio Rodrigues para a confecção dos móveis foi o trabalho anterior de mesas para os gabinetes do novo Ministério de Relações Exteriores, a ser construído posteriormente em Brasília. Como se sabe, esse trabalho fora encomendado pelo diplomata Wladimir Murtinho e pelo arquiteto Olavo Redig de Campos em visita à loja Oca (onde eram vendidos os mobiliários criados por Sergio Rodrigues), no Rio de Janeiro. 
Entre as mesas de Rodrigues, aquela que mais interessou Murtinho e Redig foi a mesa Itamaraty feita, no ano de 1959, para o ministro Horácio Lafer. A mesa para o ministro foi um sucesso e foi o início da substituição do mobiliário de século XIX, os famosos "luízes", encontrados em quantidade nas dependências do palácio do Itamaraty no Rio de Janeiro ${ }^{12}$, no famoso processo de transferência do Ministério das Relações Exteriores para Brasília. Diante disso, Gouthier visitaria Rodrigues em sua loja na cidade do Rio de Janeiro, bairro do Botafogo, para encomendar o desenho e a confecção do mobiliário para a Casa do Brasil em Roma. Foi na loja Oca que Rodrigues mostrou a Gouthier o protótipo da mesa feita para o ministro das Relações Exteriores. Tudo posto em acordo, Rodrigues começou a trabalhar, em 1960, para a realização dos móveis da Casa do Brasil em Roma. O trabalho duraria exatamente dois anos e seria finalizado em 1962.

Em quadro demonstrativo, referente às despesas da Casa do Brasil em Roma, consta o total das despesas com mobiliário e decoração juntamente com atribuição dos serviços a Sergio Rodrigues e execução pela fábrica Forma de Brescia de Carlo Hauner, antigo sócio de Rodrigues no Brasil. O total despendido com o mobiliário, decoração e serviços correspondeu à quantia de Lit. 79.350.271,00. Essa cifra, embora pareça grande (poder-se-ia dizer exorbitante), corresponde, no entanto, à décima oitava parte do que foi gasto com a compra, a reforma e a restauração do palácio Pamphili em Roma.

O documento de Hugo Gouthier, produzido como expediente de controle interno e prestação de contas do Itamaraty, descreve minuciosamente os acordos realizados na fabricação de móveis para a nova Embaixada:

Mediante autorização da Secretaria de Estado, foi, o arquiteto Sergio Rodrigues, da firma 'OCA S/A', do Rio de Janeiro, incumbido de desenhar os móveis de escritório, dentro de padrões modernos e funcionais e escolhida, para execução dos mesmos, a madeira brasileira denominada 'jacarandá', que viria do Brasil. (...) comparadas as referidas propostas, coube à firma FORMA, de Brescia, a fabricação do referido mobiliário, todo ele devidamente estudado e planejado pelos arquitetos Sergio Rodrigues e Olavo Redig de Campos, que se encontravam em Roma naquela época. (...) Assim sendo, as despesas realizadas com o mobiliário destinado à Chancelaria da Embaixada [referiam-se a] um total de 80 peças. $^{13}$
Marcelo Mari

Melancolia do moderno:

móveis esquecidos de Sergio

Rodrigues.

12. CALS, Soraya. Sergio

Rodrigues. Rio de Janeiro: Icatu, 2000, p. 233.

13. GOUTHIER, H. Op. cit., 1963, p. 160 

e mesas, foram replicadas. Entre os móveis mais conhecidos de Sergio Rodrigues estão ali: a famosa e robusta mesa Itamaraty, que é versão da mesa do ministro das Relações Exteriores em Brasília e diferente da versão da mesa, em linhas mais finas e elegantes, comercializada pela Oca nos anos seguintes; a poltrona Navona e o sofá Navona de três lugares (1960), ambos concebidos com almofadas grandes, soltas no assento e encosto; a mesa de reunião Gouthier (1960), evidente homenagem ao embaixador que concebeu a Casa do Brasil como espécie de vitrine juscelinista da brasilidade no exterior. Essa mesa tem estrutura similar ao primeiro modelo da mesa Itamaraty com pés de seção quadrada, travamento dos pés da mesa por travessa de madeira, com guarnições douradas como as utilizadas na mesa Itamaraty de Roma, toda feita em madeira de jacarandá.

A mesa Gouthier da Embaixada do Brasil na Itália é um exemplar elegantíssimo de mobiliário, pela forma austera da estrutura de madeira da mesa, o tampo ligeiramente sextavado pelo endosso de ligeiras contundências de ângulos na grande curvatura longitudinal da mesa, dando forma elíptica para o mármore rajado e cinzento. Não obstante sua beleza, dentre todos esses móveis, a poltrona Navona ganhou destaque internacional, em parte por ser robusta, larga, espaçosa e por primar especialmente pelo conforto aparentemente em excesso. Também fazem parte dos móveis acessórios do gabinete do embaixador: armário baixo, padronizado e presente em todos os espaços da embaixada para guarda de pastas, de papelada e de material de escritório; mesa de centro com estrutura em madeira de jacarandá, possuindo linhas simples, pés em seção quadrada e tampo em mármore branco; duas mesas laterais com as mesmas características.

Além desses móveis do gabinete do embaixador, não podemos esquecer da poltrona do Embaixador (1960), que foi uma poltrona realizada no ano de 1960 por Sergio Rodrigues com linhas adequadas ao conjunto do sofá de três lugares e de duas poltronas Navona do gabinete. Rodrigues comenta brevemente em pequeno texto da revista Módulo as características que modelaram a linha da família Navona e a produção da poltrona do Embaixador em consonância com os outros móveis do gabinete. No caso, a poltrona do Embaixador, que se per- 


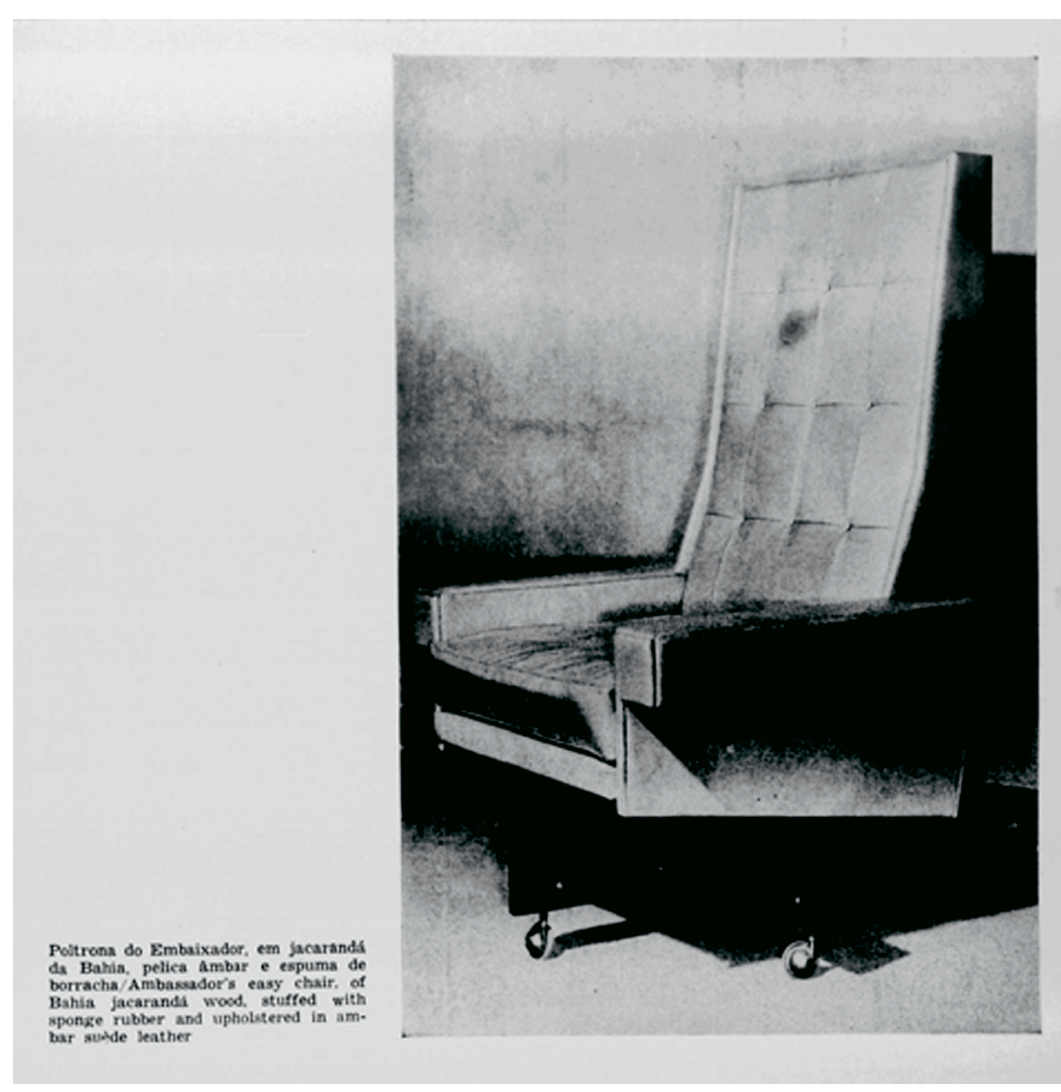

deu provavelmente por desgaste de uso, foi modelo para outra poltrona giratória, denominada Holperin, produzida posteriormente no ano de 1962. A diferença entre as duas encontrava-se nos braços da poltrona do Embaixador, que diferentemente do afinamento contido na poltrona Holperin - braços formados por placas laterais em plano contínuo entre a lateral do encosto, o próprio braço e o assento da poltrona -, mantinha com coerência a forma de um prisma quadrangular presente tanto na poltrona Navona como no sofá. É preciso salientar também que tanto a poltrona do Embaixador, como a poltrona e o sofá Navona do gabinete do Embaixador foram produzidos com estrutura em madeira de jacarandá, estofamento em espuma de borracha e revestidos com partes de pelicas de formato quadrado, costuradas, na cor âmbar.

Esses móveis guardam características muito interessantes, pois são um conjunto coetâneo tanto dos trabalhos de Sergio Rodrigues para a exposição "Casa individual pré-fabricada", realizada no espaço externo do Museu de Arte Moderna do Rio de Janeiro, em março de 1960, como da fabricação de móveis de desenho simples e de boa
134

\section{Marcelo Mari}

Melancolia do moderno:

móveis esquecidos de Sergio

Rodrigues.

Fig. 2

Poltrona do Embaixador, giratória, estofamento em poliuretano e revestimento de couro na cor âmbar, circa 1960-1962. Fotografia reproduzida pela revista Módulo (vol. 5, n. 22, p. 31, abr. 1961). 


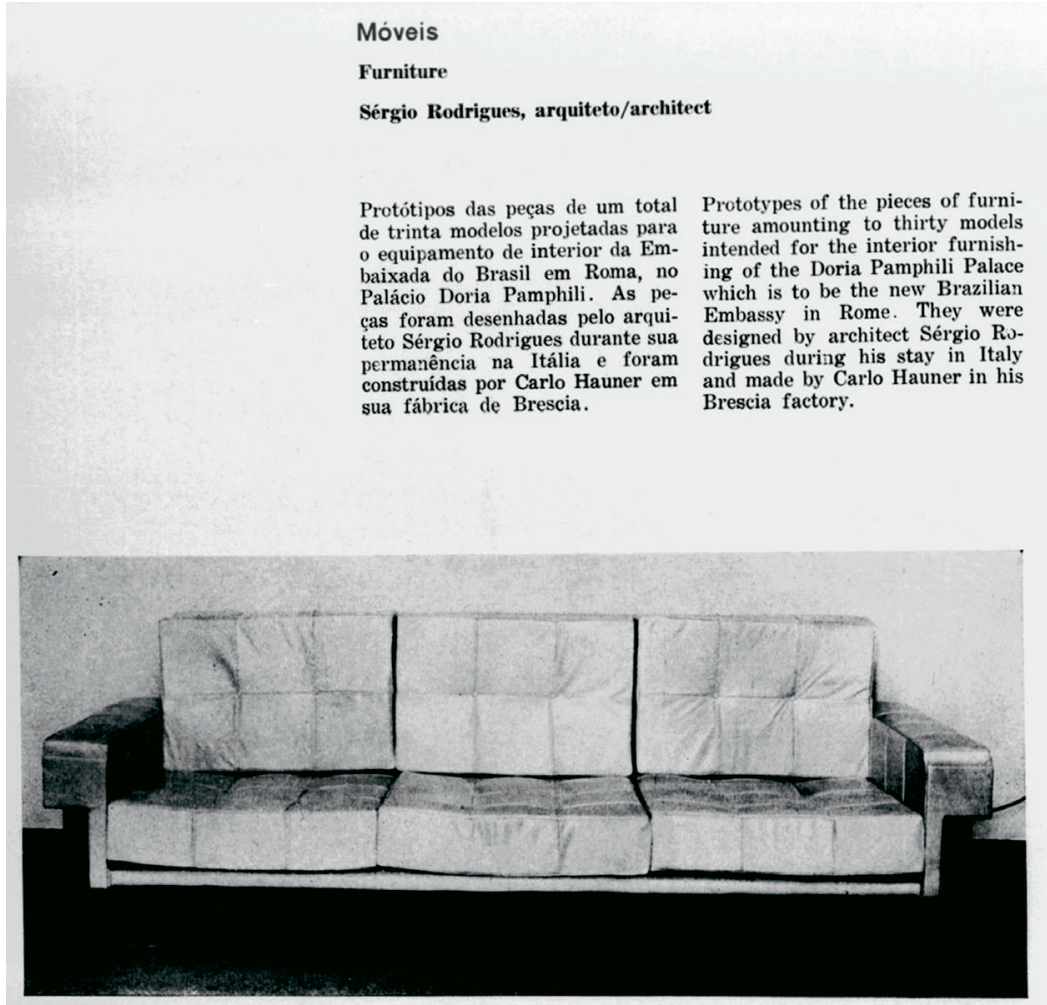

Sofá do Gabinete do Embaixador, em jacarandá da Bahia, pelica ambar e espuma de borracha/Sofa in Ambassador's orfice, made of Bahla Jacaranda stered in ambar suède leather

Fig. 3

Sofá e poltrona Navona de $1960,240 \times 90 \times 70 \mathrm{~cm}$, estrutura em madeira maciça,

criados especialmente para

o palácio Doria Pamphili.

Fotografia reproduzida pela revista Módulo (op. cit., p. 30).

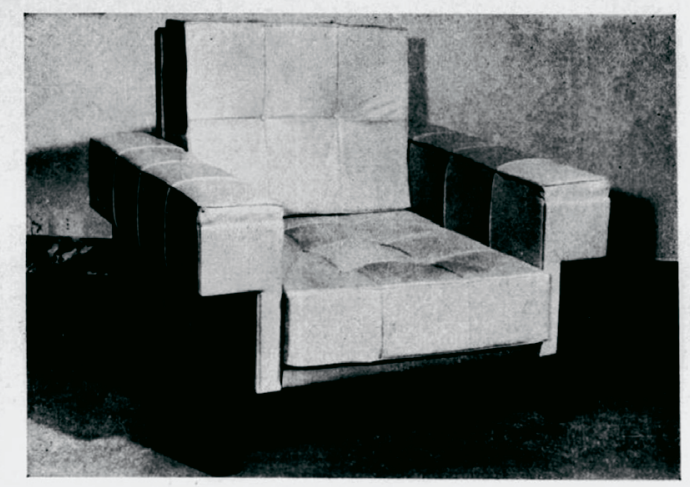

Poltrona do Gabinete do Embaixador em jacarardá da Bahia, espuma de berracha e pelica ambar/Easy chair in Ambassador's office, of Bahia jacaranda wood, stuffed with sponge rubber and upholstered in ambar suede

30

qualidade para a Universidade de Brasília em 1961 e 1962. Pode-se dizer que, os móveis de Sergio Rodrigues possuíam duas características efetivas e pouco dissociáveis: uma, de móveis com presença que se destacavam pela particularidade do desenho impetuoso com função simbólica e, outra, de móveis que primavam pelo uso corriqueiro, nem sempre comum. 
De fato, foi nesse período curto de tempo, entre os anos finais de 1950 e os iniciais de 1960, que características do móvel como ênfase na presença ou como crédito ou descrédito no uso comum, para atendimento de demandas em massa pela produção em série nas indústrias, vão ganhando acentos diferenciados. Se é notório que Rodrigues seguia os passos dos arquitetos do Rio de Janeiro, muito vinculados à dimensão suntuosa do fato arquitetônico utilizada principalmente na arquitetura oficial e na arquitetura das classes abastadas, processo que se remete à fundação de escola de arquitetura com Grandjean de Montigny até períodos mais recentes com a refundação da Faculdade de Arquitetura por Lúcio Costa no final dos anos de 1930, houve também, sobretudo a partir dos anos de 1950, uma necessidade manifesta dos arquitetos, seguidores ou não dos princípios de Le Corbusier, Bauhaus etc., de encontrar soluções de arquitetura e de urbanística para as camadas populares, pessoas comuns implicadas no processo de desenvolvimento e modernização rápida do país.

Em 1961, Sergio Rodrigues rumava em direção, ainda que em via de mão dupla, às solicitações prementes - que orientaram o governo de Juscelino Kubitschek e mais ainda o governo de João Goulart, a partir especialmente de meados do ano de 1961 até o de golpe militar. Não foi por outro motivo que Rodrigues realizou exposição de seus móveis e casa pré-fabricada no Museu de Arte Moderna do Rio de Janeiro. Ele aliava-se às preocupações em encontrar soluções arquitetônicas para as diversas classes sociais, o barateamento dos materiais de construção e a aquisição de condições tecnológicas de produzir casas em série a baixo-custo. Tudo isso somado, Rodrigues pensava na casa individual pré-fabricada e no móvel moderno para seu interior.

Todavia, no processo geral do desenho é possível verificar elementos em franca disputa que se inscreviam na produção do mobiliário moderno, que por isso ora endossavam sua característica de objeto raro, pois diferenciados no consumo e diferenciadores no status, ora se revelavam no processo de democratização da forma moderna pelo móvel de alta qualidade para atendimento de demandas sociais forçosas e muito amplas. Pode-se dizer que, enquanto vicejou a expectativa de ampliação do mercado interno para produtos em geral que não se restringiam a demandas por viveres essenciais, mas de ampliação do consumo da classe média no Brasil, não podia haver distinção clara entre qualidades de móvel de presença e de uso corriqueiro com ênfase de conotação para uso comum, emancipatório.
Marcelo Mari

Melancolia do moderno: móveis esquecidos de Sergio Rodrigues. 


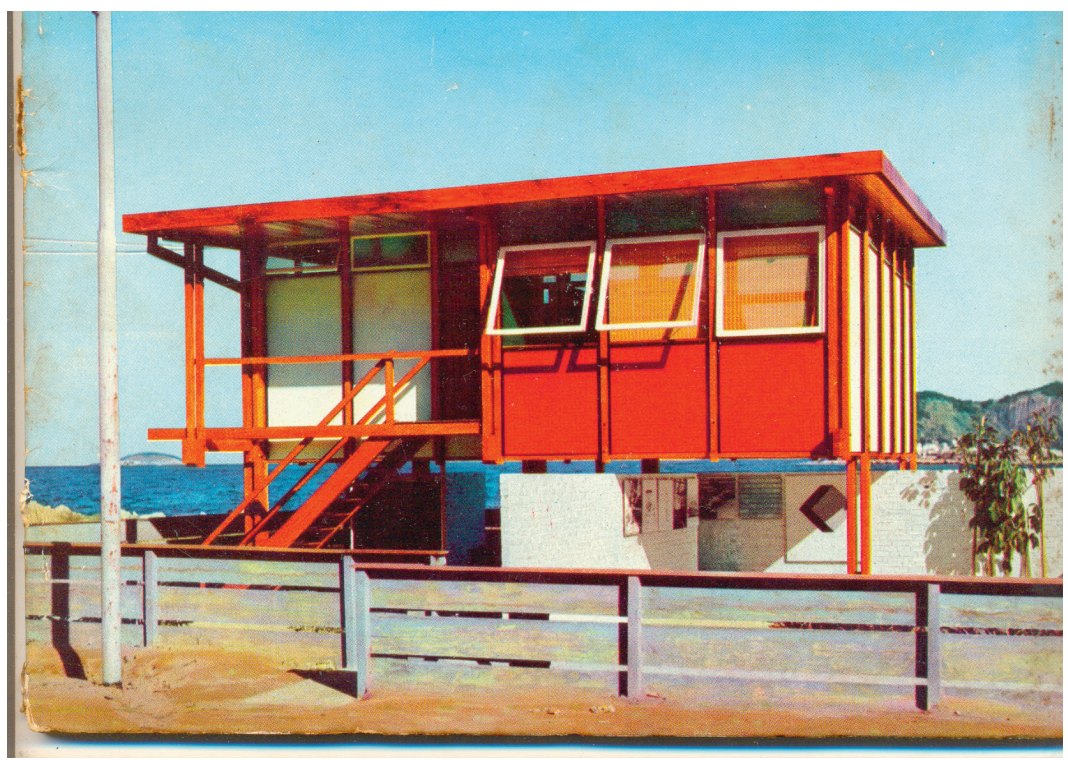

Naquele momento, em texto para o catálogo de exposição "Casa individual pré-fabricada" no MAM do Rio de Janeiro, Mário Pedrosa reforçaria o caráter coletivista e de democratização da forma moderna presentes na experimentação da fábrica Oca. A comparação do módulo arquitetônico desenvolvido por Rodrigues com as experiências da Bauhaus e particularmente com as ideias de Walter Gropius sobre a massificação da experiência moderna, sem negar a potencialidade da singularidade da reapropriação e do uso do espaço, davam sinal claro de que, para Pedrosa, o projeto moderno cuidava da dimensão social da arquitetura sem negar os aspectos de elaboração da experiência individual, da singularidade enfim. Tratavam-se de experimentos realizados para o que se pensava ser um futuro talvez não muito próximo, mas certamente viável, de aquisição da capacidade industrial produtiva da casa pré-fabricada no Brasil:

Nesta época de irreprimível individualismo, com profundo caráter anárquico e pessimista (...) que se nota no campo das artes plásticas, muito especialmente da pintura, exposição como esta, em boa hora promovida pelo MAM, é iniciativa que podemos saudar pelo seu otimismo. (...) Trata-se de

experiências em módulos pré-fabricados para habitação individual, projetados pelos arquitetos da Oca. (...) (os módulos de Rodrigues apresentam) uma solução possível, dentro de certos limites, para esse problema fundamental, o da habitação comum, popular, longe de resolvido. 14\# 
Ao contrário da condenação generalizada da arquitetura moderna como despersonalizante e, portanto, desumanizadora, Pedrosa faria um levantamento das principais correntes de produção de casas pré-fabricadas para mostrar que, grande parte das experiências e dos exemplares de arquitetura moderna mesmo a funcionalista, ligada a Walter Gropius, continha elementos de variação em sua produção e de atendimento, portanto, de impulsos estéticos individuais. A ideia de montagem da casa segundo as necessidades de seus habitantes era condição sine qua non dos melhores projetos da arquitetura moderna do pré-fabricado e não a ideia de construção de casas sob a égide implacável de um desenho arquitetônico único. Sergio Rodrigues e sua Oca apostavam na flexibilidade de adequação do espaço da casa moderna para que essa se adequasse às volições e necessidades dos que nela habitavam:

Seja como for, os modelos da Oca oferecem bastante flexibilidade para possibilitar uma escolha individual na variedade desse tipo de habitação. Graças ao módulo básico, com seus múltiplos e submúltiplos, a casa pode ser aumentada de mais de uma unidade habitacional ou espacial, quartos, varanda, decks, etc. (...) Como se trata sobretudo de montagem, asseguram os projetistas não ser necessária nenhuma equipe especializada, o que tornará seu custo ainda mais econômico, e o projeto todo ainda mais adaptável, com pequenos ajustamentos, aos mais variados programas urbanísticos: conjuntos residenciais em grandes empresas ou fábricas que se constroem fora dos centros urbanos, ou para cidades novas (metropolitanas ou satélites), grupos escolares de emergência, centros de saúde, colônias de férias, com uma unidade central coletiva e em irradiação através de decks suspensos ou caminhos cobertos que a ligam a unidades menores para casais ou famílias separadas, na periferia. ${ }^{15}$

Se, em 1960, Sergio Rodrigues seguia orientação de uma arquitetura com função social, o mesmo pode-se dizer de seus móveis, tornando dificílima aquela distinção conceitual simples entre qualidades do móvel de presença e de uso comum. Tanto isso é verdade que em foto publicada na revista Módulo do interior da casa pré-fabricada de Sergio Rodrigues em exposição no MAM do Rio de Janeiro, encontramos vários exemplares de seu mobiliário posteriormente atribuído apenas ao uso suntuário de uma classe abastada, como o banco Mocho, a poltrona Mole, cadeira Cantu baixa, mesinhas de centro e exemplares
Marcelo Mari

Melancolia do moderno:

móveis esquecidos de Sergio

Rodrigues.

15. Ibidem, p. 122-123

16. A Oca foi fundada em 1955 , depois que Sergio Rodrigues deixou de trabalhar na empresa Forma dos irmãos Carlo e Ernesto Hauner, com 
participação de Martin Eisler. A princípio, a Oca seria uma loja de comercialização dos móveis da Forma, com o tempo Rodrigues passou a vender na loja apenas seus próprios móveis e tentou produzi-los em escala não mais artesanal, mas industrial. Isso tudo em meados dos anos de 1960 . A expectativa de que a 0 ca pudesse produzir móveis em escala industrial, de boa qualidade, foi aposta feita por Rodrigues, aposta que seguia mais ou menos de perto o clima do período desenvolvimentista brasileiro.

As apostas de Rodrigues, nesse salto da produção artesanal de seus móveis para a escala industrial, somavamse aos seus projetos de casas pré-fabricadas, que era outra atividade sua. 0 arquiteto embarcava nas promessas de época, como se constata ao ler os textos publicados pela revista Módulo (1961-1963), em que relata os projetos governamentais de produção de casas e móveis. No breve período de João Goulart, Rodrigues tinha expectativa de fechar projetos, por exemplo, de construção de móveis para o governo do Rio Grande do Norte ou de construção de casas populares no estado do Amazonas. Ver: S.A. Oca

- a originalidade do estilo em função do conforto e do ambiente. In: Módulo - revista de arquitetura e artes visuais no Brasil, Rio de Janeiro, $n$. 29 , p. 28, ago. 1962. da sociedade brasileira, recém-saída do processo de abusos e iniquidades de regime escravocrata do século XIX, com mandos e desmandos da elite política e econômica, a segregação do acesso aos objetos modernos, feitos por Sergio Rodrigues ou por outros arquitetos brasileiros de talento, nada mais era do que a reafirmação da ordem de privilégios e desigualdades pela ordem simbólica inscrita na forma moderna.

$\mathrm{O}$ fato de se poder objetar que se tratava de uma exposição em museu e daí Sergio Rodrigues colocar na casa pré-fabricada, seus móveis de consumo de luxo, não nega a potencialidade inscrita em futuro outro em que ficava evidente que havia uma adequação daquele móvel, de tipo nacional, de qualidade à arquitetura do pré-fabricado da casa moderna. Se o desenho operava em dois âmbitos distintos, a saber: um, de consumo conspícuo e, outro, de dimensão social da arte e da arquitetura, com o golpe militar e muito posteriormente com a consagração internacional de Rodrigues na ordem do dia, o pêndulo girou para o interesse pela forma renovadora, mas aparentemente esvaziada de sentido social amplo e para a limitação do parco conteúdo social e estético em benefício do consumo ostensivo de uma elite brasileira atrasada. Isso quando o consumo era de fato contemplado com o gosto pelo moderno.

No ano de 1962, depois da ocasião em que Darcy Ribeiro confiara a produção de móveis para a Universidade de Brasília à firma Oca, persistia a ideia de que arquitetura e mobiliário formavam uma totalidade e não haveria, pois, sentido de se construir uma casa pré-fabricada sem aparelhá-la com os móveis do próprio Sergio Rodrigues. Justamente, o mesmo ideal que havia levado à produção de móveis para a UnB segundo princípios de beleza e economia formal tinha oportunizado a construção de casas pré-fabricadas para camadas populares pelo governo do Amazonas ${ }^{16}$. Arquitetura e mobiliário estavam juntos na produção de uma realidade de dimensão social nova no Brasil, concluindo-se que o mais refinado desenho de móveis estava estreita e potencialmente atrelado a projetos sociais tais como os de realização de casas populares, sem nos olvidarmos de que foram desde o início até o fim pensados sempre com muita qualidade no desenho e no material utilizados.

Ainda que o projeto das casas pré-fabricadas no estado do Amazonas não tivesse saído do papel, na Universidade de Brasília a ideia de Darcy Ribeiro de fazer experimentos e produzir soluções simples susce- 
tíveis de serem adotadas na vida cotidiana foram exitosas. Nas palavras de Rodrigues, Darcy Ribeiro, como reitor da Universidade, convidou-o para fazer o mobiliário da Universidade seguindo aquilo que era a tônica de época, dele e de outros arquitetos da dimensão social da arquitetura e do mobiliário modernos, a ideia de possibilidade de se produzir em série, com muita qualidade no desenho e no material, isto é, Darcy Ribeiro queria "uma coisa simplíssima. Queria algo com material bom, de jacarandá. Mas que fosse o mais simples possível, para mostrar que se poderia fazer uma coisa boa, com um bom material, mas absolutamente simples." ${ }^{17}$ É isso o que também se conclui em artigo publicado sobre as atividades da Oca na revista Módulo. Possivelmente o texto seja do próprio Sergio Rodrigues, embora não haja referência de quem o escreveu:

À Oca foi confiada, recentemente, toda a decoração da Universidade de Brasília, e o governo do Amazonas, por outro lado, acaba de encomendar casas de módulos pré-fabricados, projetadas por essa empresa, a fim de substituírem os barracos palafitas que margeiam o rio-mar. A responsabilidade e diversidade dessas tarefas - seja a adequação necessária de criações a uma casa de ensino destinada a ser núcleo de convergência cultural e refletir o moderno pensamento brasileiro, seja a solução habitacional em grande escala para uma população condicionada ao meio, com reflexos positivos em seu desenvolvimento social - dão a medida do prestígio alcançado por aquela firma de arquitetura e interiores e pelo conceito de estilo que colocou em prática. Tal princípio é o de que a originalidade no estilo, tanto em relação à decoração quanto à linha arquitetônica deve obedecer às exigências de conforto do indivíduo e do ambiente que o cerca. Para Sergio Rodrigues e seus companheiros, o axioma funciona a ponto de tornarem indissolúvel, em seus projetos, a união entre a arquitetura e a decoração, com excelentes resultados. ${ }^{18}$

O processo de modernização conservadora que se desencadeou no período pós-ditadura civil-militar de 1964, reforçou no Brasil o interesse pelo móvel de presença em detrimento de sua qualidade de uso comum. Dito isso é fácil entender a contradição inerente entre o desenho do móvel e as condições de sua produção que iria se resolver da pior maneira possível, a partir de 1964, com a restrição de acesso ao móvel moderno de qualidade para as maiorias constituídas da população e com a consagração internacional dos móveis do arquiteto como verdadeiras obras de arte, concebidas como peças únicas, sem
Marcelo Mari

Melancolia do moderno:

móveis esquecidos de Sergio

Rodrigues.

17. CALHEIROS, Alex; MARI, Marcelo; RUFINONI, Priscila. Mobiliário moderno: das pequenas fábricas ao projeto da UnB. Brasília: Editora da UnB, 2014, p. 192-193.

18. S.A. Oca - a originalidade do estilo em função do conforto e do ambiente, op. cit., p. 28. 
ARS possibilidade de barateamento e garantidoras tanto quanto de status de ano 15 genialidade para o produtor da forma moderna quanto como de status n. 29 social diferenciado para quem as possui, isto é, possui objeto fetichizado, orientado pela esfera da raridade.

Com a estagnação da modernização brasileira e a visível retração das fábricas moveleiras, restou somente aos arquitetos reforçarem suas posições-chave para manutenção da divisão social na produção e trabalharem com a escassa elite endinheirada. Nesse sentido, por muito tempo ainda, depois da crise do golpe militar e o período de abertura nos anos de 1980, os móveis de presença de Sergio Rodrigues ganharam relevo e forjaram a identidade do desenho do arquiteto ligado exclusivamente ao reconhecimento internacional e ao luxo, na utilização ostensiva da madeira de boa qualidade, da pelica e de toda sorte de materiais encontrados e trabalhados no Brasil. Independentemente de seus projetos de função social muito explícita, Sergio Rodrigues tornava-se diferenciado e seus móveis, objetos cultuados. Em suma, o nome do arquiteto Sergio Rodrigues foi forjado conjuntamente com o processo histórico de fim da crença nas utopias modernas e com a interrupção do ciclo breve, mas virtuoso, de criação de pequenas fábricas de mobiliário moderno. Todavia, na Casa do Brasil em Roma, a orientação geral era exatamente a de se promover de melhor maneira possível a imagem e a representatividade do país no exterior.

Além do mobiliário do primeiro escalão na Embaixada do Brasil em Roma, Sergio Rodrigues produziu móveis para os outros escalões do funcionalismo e salas de escritório e de reuniões da Embaixada. Entre esses móveis é possível encontrar uma variante da mesa Inge, de 1958, com estrutura de madeira de lei maciça, tampo e gaveteiro folheado; nessa mesma linha de simplicidade e de obediência ao desenho ortogonal, encontram-se mesas com gaveteiro e mesas em formato de "L" também com gaveteiro; a poltrona e o sofá Odilon de três lugares; pequena poltrona com estrutura em madeira maciça, com braços em plano contínuo com as laterais do encosto, estofamento do assento e do encosto em borracha revestido com partes de pelicas de formato quadrado, costuradas, na cor âmbar. Essas pequenas poltronas se assemelhavam à poltrona Navona (e também à poltrona do Embaixador) por possuírem estrutura de proporcionalidades comuns, mas estofamentos mais parcimoniosos. Além da mesa aparentada à mesa Inge e de poltrona mais delgada aparentada com a Navona, é possível encontrar ainda 
na Casa do Brasil em Roma, cadeira de braço variante da cadeira de braços Tião (1959) e a cadeira de escritório, com estrutura em madeira, estofamento em espuma de borracha e revestimento de couro assemelhada à cadeira de escritório Betxo, de 1963.

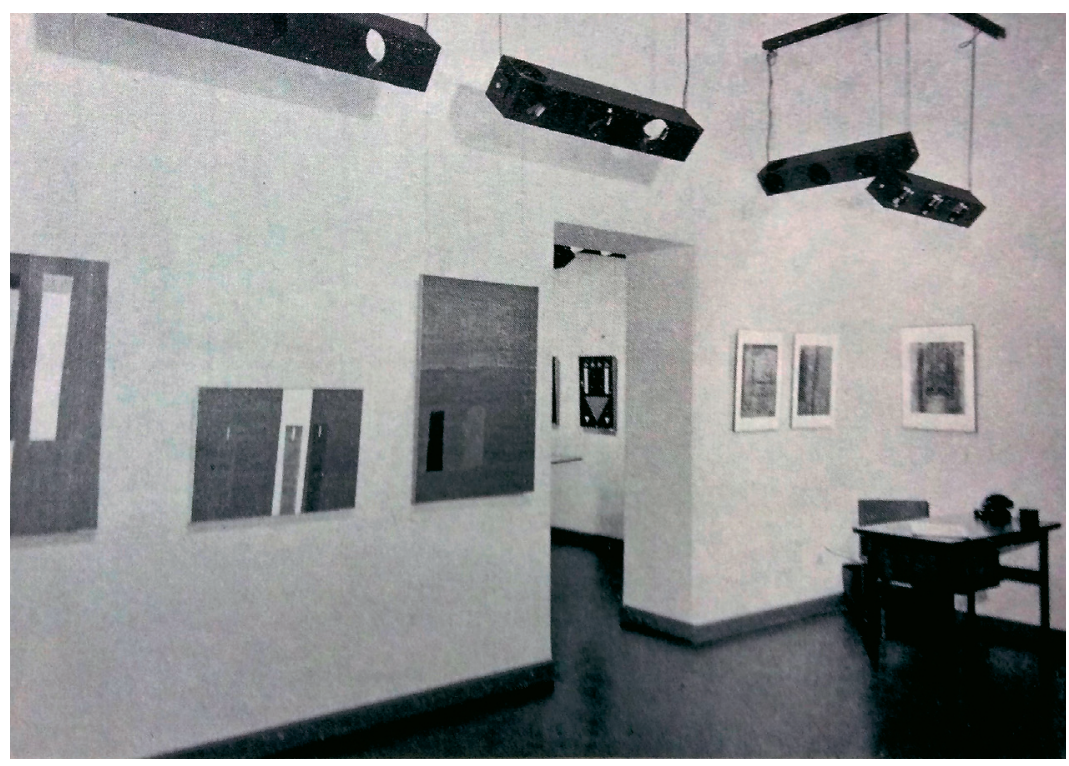

De fato, tanto os móveis da sala do embaixador como o sofá Navona e as duas poltronas Navona, a mesa de centro para o conjunto do sofá e das poltronas, além de mesas auxiliares, de mesas auxiliares com gaveta, da mesa Vianna (1961), como também a mesa Inge e sua variação, mais a mesa Lacerda (1958), são em geral móveis caracterizados pelo uso da madeira de jacarandá, no caso da Embaixada brasileira, especificação a que chegara Gouthier em conversa com Sergio Rodrigues, trazendo como característica no desenho algo que hoje não ressalta a lembrança afetiva do móvel de Rodrigues, quase sempre associado à linha sinuosa, à curvatura elegante. Ocorre que os móveis de escritório (em suas variações tais como mesa de recepção, mesa de datilografia, mesa com gaveteiro e mesa em "L") da embaixada têm como característica principal a seção quadrada das partes e da estrutura como um todo, preponderantemente retilínea e baseada, portanto, nas linhas ortogonais.

Possível de ser denominada linha Inge, os móveis de escritório de Rodrigues para a Embaixada do Brasil, naquele momento de muitos testes, experimentações e descobertas, são resultado de uma

\section{Marcelo Mari}

Melancolia do moderno: móveis esquecidos de Sergio Rodrigues.

Fig. 5

Galeria da Embaixada com mesa Inge ao fundo, 1960. Fotografia reproduzida em Casa do Brasil em Roma: palácio Doria Pamphili; histórico e documentação. Roma: SEPRO, 1963, s.p. 
adequação estritamente observada entre forma e função, menos do que da incorporação do mobiliário ao conceito fetichizado de móvel como obra de arte. Em um momento em que Gropius e seus congêneres eram rotulados, não sem motivos escusos, de funcionalistas ou redutores da forma arquitetônica a tipos invariantes, Sergio Rodrigues (naquele momento) não se deixará contaminar por isso, pois essa perspectiva utópica fica evidente em sua arquitetura pré-fabricada e em seus móveis. Todos atendiam a elemento vital de um país que estava condenado ao moderno como processo de emancipação social com o fim das desigualdades geradas pelo passado iníquo da escravidão na conjuntura colonial, com o início de transformação radical das estruturas - que nos ainda mantinham em condição periférica de exploração internacional para conveniência de poucos - e inserção, por superação, em um novo estágio mais elevado de vida, que seria muito possível de se realizar em plano local e global.

Fig. 6

Variante de mesa Inge, com seção quadrada, estrutura ortogonal em madeira maciça, gaveta lateral e tampo folheado. Arquivo particular do autor, 2015.

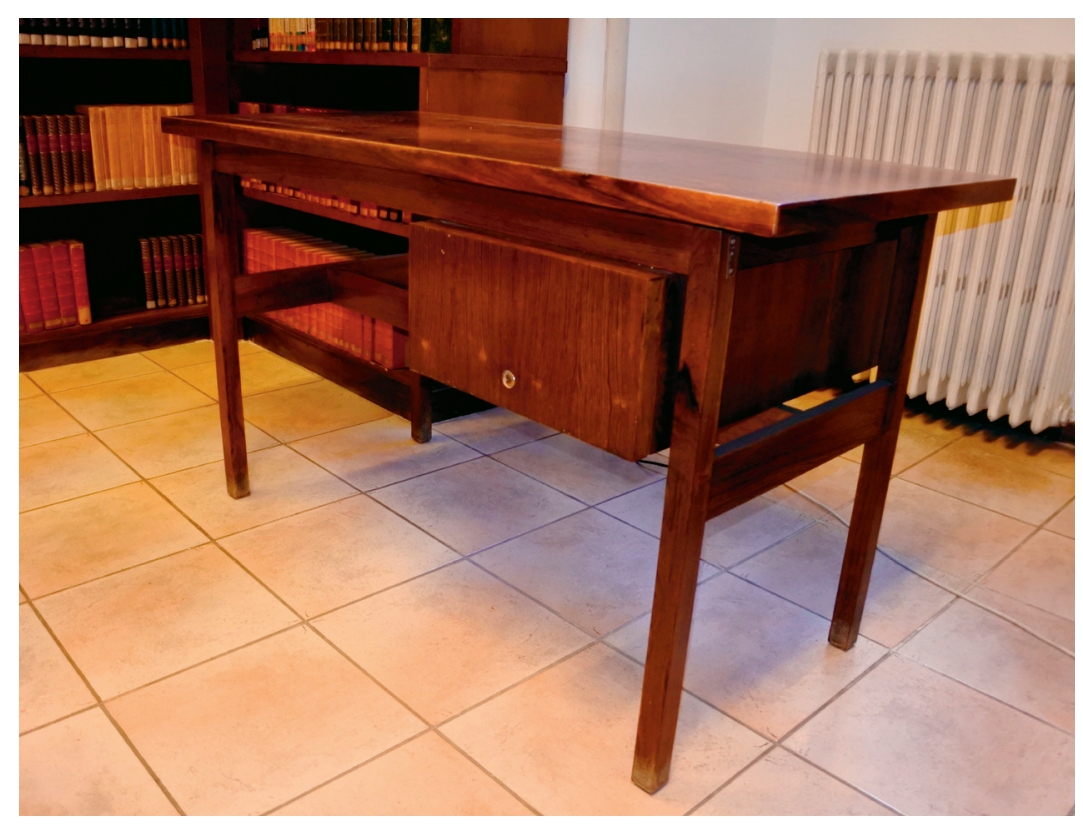

Para a confecção dos móveis da Casa do Brasil, Carlo Hauner foi apoio decisivo de Sergio Rodrigues na Itália, pois Hauner tinha grande conhecimento de fabricação de móveis; os dois já tinham trabalhado juntos na firma Móveis Artesanal. Apesar da controvérsia da afirmação, a perspectiva de Hauner esteve envolvida com os resultados de democratização da forma moderna inscritos no uso de novos materiais 
barateados pelos processos novos de industrialização. Nesse sentido, a escolha de material tradicional para a fabricação de móvel no Brasil, isto é, a madeira maciça, por Sergio Rodrigues, e não o compensado e o ferro ou aço tubular, indicava o apreço do arquiteto brasileiro pela dimensão artesanal do móvel. Dimensão artesanal que se, de um lado, revelava ainda nossa condição retardatária na aquisição e na implementação de processos modernos de produção em massa, de outro lado, garantia a possibilidade de maior de experimentação, invenção e renovação formal, coisa que até certo ponto havia ocorrido com a produção brasileira.

À parte isso, a encomenda de móveis para a Embaixada brasileira tinha a característica de atender burocratas de alto-escalão em funções estratégicas de representação do Brasil no exterior e característica peculiar de refletirem o espírito contagiante da construção da nova capital do Brasil, Brasília. De um modo ou de outro, Sergio Rodrigues fez parte daquele grupo de arquitetos que acreditou nas potencialidades da arquitetura e do urbanismo suscetíveis de contribuir para o redesenho da sociedade brasileira. Afinal parecíamos viver uma situação inédita, um tempo novo em que o protagonismo da modernização brasileira se fazia sentir em perspectivas emancipatórias de um país até há pouco tempo marcado por uma série de arcaísmos.

Todo esse espírito de modernização otimista parece estar cristalizado no conjunto de móveis da Casa do Brasil. Quando ali ingressamos pela primeira vez, a sensação nítida que tivemos fora justamente de estar entrevendo, a partir de todos aqueles móveis ali, a imagem cristalizada de uma época passada nossa. Isso se explica, em parte, pelo fato de a Embaixada não ter sofrido do imperativo de atualização ou modernização posterior ao momento Juscelino Kubitschek, de que foram vítimas muitos dos edifícios públicos no Brasil por força do atendimento de interesses muitas vezes escusos de empresas que oferecem novos móveis em licitações duvidosas para governos.

O conjunto da mobília moderna de Sergio Rodrigues na Casa do Brasil em Roma poderia ter servido de modelo para nossas embaixadas e repartições consulares no mundo afora, mas não houve tempo nem dinheiro para que essa ideia persistisse e florescesse. A utopia proposta pelo mobiliário de Rodrigues não foi completada. Passado o ciclo virtuoso dos anos desenvolvimentistas, tudo no Brasil recrudesceu e a ditadura civil-militar interrompeu o projeto que se desenhava em tônica nacional. Quando ocorreu a abertura política nos anos de 1980 e se
144

Marcelo Mari

Melancolia do moderno:

móveis esquecidos de Sergio

Rodrigues. 
ARS começou a revalorizar o que havia sido feito em termos de arte, mobiano 15 liário e arquitetura, naqueles anos anteriores ao golpe, muita coisa foi

n. 29 recuperada pela via mercantil, contudo já era outra época e o projeto inicial não era mais possível de ser vivido.

\section{Bibliografia complementar}

ARGAN, Giulio Carlo. Walter Gropius e a Bauhaus. Lisboa: Presença, 1990.

CORBISIER, Roland. Formação e problema da cultura brasileira. Rio de Janeiro: ISEB, 1958.

DREIFUSS, René Armand. 1964: A conquista do Estado. Petrópolis: Vozes, 1981.

GOMES, Angela Maria de Castro. O Brasil republicano: sociedade e política (1930-1964). Rio de Janeiro: Bertrand Brasil, 1996.

GROPIUS, Walter. Bauhaus: Novarquitetura. São Paulo: Perspectiva, 1972 MARI, Marcelo; RUFINONI, Priscila. Ditadura, modernização conservadora e universidade: debates sobre um projeto de país. Goiânia: UFG, 2015.

PEDROSA, Mario. A opção brasileira. Rio de Janeiro: Civilização Brasileira, 1966.

. A opção imperialista. Rio de Janeiro: Civilização Brasileira, 1966. SANTOS, Maria Cecilia Loschiavo. Móvel moderno no Brasil. São Paulo: Olhares, 2015.

SCHWARZ, Roberto. Sequências brasileiras. São Paulo: Companhia das Letras, 1999.

. O pai de família e outros escritos. São Paulo: Paz e Terra, 1992.

SKIDMORE, Thomas. Brasil: de Getúlio a Castelo. São Paulo: Paz e Terra, 1982.

TAVARES, Flávio. 1964: o golpe. Porto Alegre: Editora L\&PM, 2014.

TOLEDO, Caio Navarro de. ISEB: fábrica de ideologias. Campinas: Editora da Unicamp, 1996. 